Abstract P32 Table 1 Partner notification of chlamydia positive patients in 2011

\begin{tabular}{|c|c|c|c|c|c|c|c|c|c|c|}
\hline & March & April & May & June & July & August & September & October & November & December \\
\hline Chlamydia positives & 38 & 39 & 49 & 67 & 40 & 68 & 63 & 43 & 36 & 39 \\
\hline$\%$ of positives with consent for PN & 8 & 10 & 16 & 34 & 40 & 32 & 38 & 47 & 56 & 62 \\
\hline
\end{tabular}

Methods A sexual health adviser was appointed to manage the positive Chlamydia diagnoses made out with the specialist services. This service commenced in March 2011 and coincided with the roll out of Chlamydia and Gonorrhoea PCR testing to these areas. Providers were informed to seek consent for referral at the time of testing and acquire the individual's mobile number. The PN service was advertised through email to all providers who undertake testing and in addition, educational sessions and updates were provided.

Results The table shows progressive improvement in the uptake of PN over the course of the year (see abstract P32 table 1).

Discussion Despite a marked increase in the referral rate for PN, uptake remains suboptimal. Specific GP practices that rarely test for Chlamydia or refer for PN are identified and contacted, reminding them of the importance of PN

\section{P33 GONORRHOEA IN YOUNG HETEROSEXUALS: OUTBREAK MANAGEMENT AND SAFE SEX MESSAGES}

doi:10.1136/sextrans-2012-050601c.33

${ }^{1} \mathrm{~K}$ Foster, ${ }^{*} \mathrm{~A}$ Waldram, ${ }^{2} \mathrm{~N}$ Sankar, ${ }^{2} \mathrm{~N}$ Jeffrey, ${ }^{3} \mathrm{~J}$ Stonebridge, ${ }^{4} \mathrm{~S}$ Bellamy. ${ }^{1}$ Health Protection Agency; ${ }^{2}$ Newcastle Hospitals Community Health, Sexual Health Services, Newcastle upon Tyne, UK; ${ }^{3} \mathrm{NHS}$ North of Tyne, Newcastle upon Tyne, UK; ${ }^{4}$ Northumberland Sexual Health Service, Newcastle upon Tyne, UK

Background Increases in gonorrhoea infection in young heterosexuals have been reported in two distinct areas of the North East of England over the past 6 months. Multi-agency working between GUM, public health, health protection and communication teams has attempted to increase awareness and reduce transmission. From initial case and partner notification information, there appeared to be misunderstandings about the routes and risks of transmission, along with a perception that a negative chlamydia test could be regarded as an STI "all clear".

Methods Following the report of increase in area 1 in September 2011, a number of interventions were put in place, including enhanced surveillance, network mapping of contacts and cases, raising awareness among healthcare professionals, other organisations working with young people and with young people themselves. An increase in cases in area 2 was reported in November 2011. Similar interventions are being introduced and ongoing work to explore any links between the clusters.

Results 65 cases of gonorrhoea have been reported in area 1 since May 2011 (compared to a usual annual number of 15); in area 2 clustering of cases has occurred at higher rates than previously seen, although overall number of cases has not increased. Partner notification and network mapping has shown multiple casual partners although no large extended sexual networks. Dual-testing of chlamydia screening samples is now being considered to further outbreak control. We report the lessons learnt from managing these two clusters and how they can be applied to future STI clusters.

\section{P34 PARTNER NOTIFICATION FOR HIV: A REGIONAL OUTCOME AUDIT}

doi:10.1136/sextrans-2012-050601c.34

${ }^{1} \mathrm{G}$ Bell, ${ }^{*} \mathrm{~S}$ Green, ${ }^{1} \mathrm{~T}$ Cox, ${ }^{1} \mathrm{~S}$ Naylor, ${ }^{2} \mathrm{P}$ Bennett, ${ }^{2} \mathrm{~S}$ Dudley, ${ }^{3} \mathrm{~J}$ Martin, ${ }^{3} \mathrm{~S}$ Parsons, ${ }^{4} \mathrm{~J}$ Rothwell, ${ }^{5} \mathrm{D}$ Allen, ${ }^{6} \mathrm{~W}$ Beckett. ${ }^{1}$ Royal Hallamshire Hospital, Sheffield, UK;
${ }^{2}$ Rotherham District General Hospital, Rotherham, UK; ${ }^{3}$ Chesterfield Royal Hospital Derbyshire, UK; ${ }^{4}$ Doncaster and Bassetlaw Hospitals NHS Foundation Trust, Doncaster, UK; ${ }^{5}$ Barnsley District General Hospital, Barnsley, UK; ${ }^{6}$ Lincolnshire Community Health Services NHS Trust, Sleaford, UK

Background Partner notification (PN) for HIV facilitates early diagnosis among those at highest risk. Health advisers and HIV nurses from eight clinics (7 GUM, 1 ID) formed a regional HIV network public health group to optimise $\mathrm{PN}$ across the region by sharing intelligence of local HIV transmission and monitoring practice against national guidelines and standards. Since there is no national standard for HIV PN outcomes, we undertook a baseline local audit to inform discussion on the possibility of setting a regional standard. Objective To conduct a baseline audit for HIV PN outcomes across the regional HIV network.

Methods HIV services across the network undertook a retrospective case note review of all patients newly diagnosed with HIV in 2011. Data were collected on the number of partners verified/reported as tested negative/positive before the index, or within 90,180 or 360 days, following patient or provider referral.

Results Results received from 7/8 clinics are presented below (see abstract P34 table 1).

Conclusions Overall PN outcomes are good across the region, although there was wide variation between clinics which makes it difficult to set a single regional standard that is both challenging and achievable for all. Outcomes were verified for most partners, but not possible if tested at an unknown clinic or abroad. The majority of tested partners attended within 3 months, but a small number took up to a year, suggesting PN efforts should continue until the partner is deemed untraceable.

Abstract P34 Table 1 HIV partner notification

\begin{tabular}{lll}
\hline & Range per clinic & Overall \\
\hline $\begin{array}{l}\text { Number partners verified tested } \\
\text { per case }<90 \text { days }\end{array}$ & $0.17-1.3$ & $1.05(118 / 112)$ \\
$\begin{array}{l}\text { Number partners verified or reported } \\
\text { tested per case }<90 \text { days }\end{array}$ & $0.66-1.33$ & $1.15(129 / 112)$ \\
$\begin{array}{l}\text { Number partners verified tested } \\
\text { per case }<1 \text { year }\end{array}$ & $0.17-1.38$ & $1.17(131 / 112)$ \\
$\begin{array}{l}\text { Number partners verified or reported } \\
\text { tested per case }<1 \text { year }\end{array}$ & $0.66-1.53$ & $1.27(142 / 112)$ \\
\hline
\end{tabular}

\section{P35 A COLLABORATIVE APPROACH TO CONTROLLING AN HIV OUTBREAK AMONG INTRAVENOUS DRUG USERS}

doi:10.1136/sextrans-2012-050601c.35

${ }^{1} \mathrm{G}$ Bell, ${ }^{*}{ }^{2} \mathrm{~T}$ Devey, ${ }^{1} \mathrm{~A}$ Cope, ${ }^{1} \mathrm{C}$ Evans, ${ }^{1} \mathrm{C}$ Hughes, ${ }^{1} \mathrm{~S}$ Naylor, ${ }^{1} \mathrm{~J} \mathrm{M}$ Greig, ${ }^{1} \mathrm{~A} J$ Tunbridge, ${ }^{2} \mathrm{O}$ Lagundoye, ${ }^{3} \mathrm{R}$ McNaught. ${ }^{1}$ Sheffield Teaching Hospitals NHS Foundation Trust, Sheffield, UK; ${ }^{2}$ Sheffield Health and Social Care Trust, Sheffield, UK; ${ }^{3}$ South Yorkshire Health Protection Unit, South Yorkshire, UK

Background In 2008 an intravenous drug user (IVDU) admitted to the infectious diseases unit was diagnosed with late-stage HIV. He named five injecting partners, of whom three tested negative for HIV, one refused, and one was untraced. In early 2010 another IVDU was diagnosed, naming two injecting partners of the previous case who had either declined or tested negative in 2008. 